\title{
STUDI KEPUTUSAN PEMBELIAN MAKANAN OLEH-OLEH KHAS SURABAYA: PERAN BRAND AWARENESS DAN KUALITAS PRODUK
}

\author{
Candra Purba Wisesa \\ Universitas Negeri Surabaya \\ candrapurba23@gmail.com
}

\begin{abstract}
Travelling is a fun and memorable activity. During tourism activities, tourists not only walk around but also go shopping. Including one of them is to buy souvenirs typical of the tourist areas visited. This study aims to analyze the effect of brand awareness and product quality on purchasing decisions. Respondents in this study were consumers who were at least 20 years old who had made a purchase. The sampling method uses nonprobability sampling, and the sampling technique using judgmental sampling. The sample used in this study amounted to 220. The data is collected using a questionnaire and analyzed using multiple linear regression. The result shows that brand awareness influences purchasing decisions. Product quality affects purchasing decisions.
\end{abstract}

Keywords: brand awareness; product quality; purchase decision.

\section{PENDAHULUAN}

Surabaya yang menjadi kota terbesar kedua di Indonesia juga memiliki banyak tempat wisata yang menarik dan juga oleh-oleh khas Surabaya yang patut dibawa sebagai buah tangan kenang-kenangan setelah mengunjungi kota Surabaya (tourdejava.com, 2015). Berdasarkan hasil wawancara dengan Owner Lapis Kukus Surabaya Pahlawan, Lapis Kukus Surabaya Pahlawan merupakan salah satu oleholeh khas Surabaya yang didirikan pada tahun 2015 dan perkembangannya sangat pesat. Di wilayah Surabaya banyak outlet-outlet Lapis Kukus Surabaya Pahlawan yang bertebaran. Hampir di semua wilayah Surabaya baik Surabaya Timur, Surabaya Utara, Surabaya Barat, Surabaya Selatan, ada Outlet Lapis Kukus Surabaya Pahlawan.

Tabel 1.

PENJUALAN LAPIS KUKUS SURABAYA PAHLAWAN 2019

\begin{tabular}{cl}
\hline Bulan & Penjualan \\
\hline Maret & 15.652 box \\
April & 13.195 box \\
Mei & 11.556 box \\
\hline
\end{tabular}

Sumber: data hasil wawancara

Tabel 1 menunjukkan bahwa 3 bulan terakhir penjualan Lapis Kukus Surabaya Pahlawan mengalami penurunan pembelian Terdapat banyak faktor yang menyebabkan penurunan pembelian. Penelitian dari Okkysantria (2014) menyatakan bahwa ada faktor-faktor yang menimbulkan pengaruh perilaku konsumen pada keputusan pembelian sebuah produk. Indikator keputusan pembelian yang digunakan oleh Okkysantria (2014) adalah jumlah pembelian, produk yang dipilih merupakan yang terbaik, dan waktu pembelian.

Merek juga adalah salah satu alat yang menghubungkan dari perusahaan pada konsumen serta sebuah merek juga menjelaskan suatu produk yang ditawarkan oleh perusahaan. Reputasi sebuah merek menimbulkan sebuah pengaruh pada kinerja perusahaan, baik finansial maupun bukan finansial. Ekuitas merek adalah seuatu aset dan liabilitas merek yang berhubunngan dengan suatu merek, nama dan simbol yang mampu menaikkan nilai dari sebuah produk atau jasa pada perusahaan ataupun pada pelanggan (Aaker, 1997:22). 
Ekuitas merek memiliki beberapa elemen, salah satunya adalah brand awareness yang merupakan kemampuan yang dimiliki calon konsumen untuk mengingat dan mengenali suatu merek merupakan bagian dari suatu produk tertentu (Aaker, 1997). Selanjutnya pendapat Kotler dan Keller (2009:179), brand awareness adalah sebuah kemampuan untuk mendiskripsikan dan memahami suatu merek dengan cukup rinci untuk memutuskan membeli suatu produk. Aaker (1997:90-92) menyebutkan ada beberapa tingkatan pada brand awareness mulai terendah hingga tingkat tertinggi yaitu : unaware of brand, brand recognition, brand recall, dan top of mind.

Di dalam bauran pemasaran (Marketing mix), salah satu alat pemasaran yang dapat menjadikan konsumen terpenuhi keinginan dan kebutuhannya adalah produk. Yang termasuk komponen atribut produk yang bisa memengaruhi konsumen dalam melakukan keputusan pembelian produk adalah kualitas produk (Kotler dan Amstrong, 2008:103).

Kualitas produk merupakan alat atau fitur dan ciri khas yang dimiliki sebuah produk yang dapat memuaskan kebutuhan yang dinyatakan oleh konsumen sehingga dapat mempertimbangkan untuk melakukan pembelian (Kotler dan Keller, 2009). Kotler dan Amstrong (2008:272) juga menyebutkan kualitas produk adalah salah satu hal yang dipertimbangkan konsumen untuk melakukan pembelian.

Menurut Yaphyaputra dan Maichal (2018)., bila brand awareness suatu produknya tinggi maka akan berpengaruh terhadap tingkat pembelian konsumen yang semakin tinggi dan juga sebaliknya. Dengan demikian, apabila kesadaran merek konsumen terhadap suatu produk semakin tinggi maka berpengaruh terhadap penjualan.

Penelitian ini bertujuan untuk menganalisis pengaruh brand awareness dan kualitas produk terhadap keputusan pembelian Lapis Kukus Surabaya Pahlawan.

\section{KAJIAN PUSTAKA DAN PENGEMBANGAN HIPOTESIS}

\section{Keputusan Pembelian}

Schiffman dan Kanuk (2004) menuturkan bahwa keputusan pembelian merupakan tindakan untuk memilih dari dua atau lebih pilihan alternatif yang dilakukan oleh konsumen dan selanjutnya memutuskan membeli produk yang ditawarkan.

Menurut Kotler dan Keller (2009), keputusan pembelian memakai beberapa dimensi yaitu pemilihan merek, pemilihan produk, pemilihan suplier atau pemasok, waktu untuk melakukan pembelian, kuantitas atau jumlah pembelian, dan cara pembayaran. Indikator keputusan pembelian pada penelitian ini mengacu pada penelitian Okkysantria (2014) menggunakan indikator-indikator berikut untuk mengukur keputusan pembelian: produk yang terbaik sebagai pilihan, jumlah pembelian dan waktu pembelian.

\section{Brand Awareness}

Pendapat Kotler dan Keller (2009:179), brand awareness/ kesadaran merek ialah kesanggupan dari konsumen untuk mendiskripsikan, mengingat, dan mengakui suatu merek dengan cukup rinci untuk melakukan pembelian. Dengan kata lain, brand awareness adalah kemampuan calon konsumen untuk mendiskripsikan merek yang muncul dalam angan-angan konsumen ketika sedang memikirkan produk tertentu.

Tingkatan brand awareness menurut Aaker (1997:90-92) adalah sebagai berikut. (1) Top of Mind adalah menggambarkan merek yang kali pertama muncul dibenak responden dan disebutkan responden. Artinya merek tersebut yang disebutkan pertama kali muncul dalam benak konsumen. (2) Brand Recall adalah pengingatan kembali merek tanpa bantuan seseorang untuk menyebutkan merek tersebut dalam suatu produk, ini diistilahkan pengingatan kembali "unaided recall". (3) Brand Recognition adalah tingkat terendah brand awarenes, bahwa responden dapat mengenal merek dengan bantuan (aided recall) saat akan mengingat kembali. (4) Unware of Brand (Tidak menyadari 
brand) adalah tingkat paling rendah dalam piramida brand awarenes di mana konsumen tidak menyadari adanya suatu merek meskipun melalui alat bantu.

Indikator brand awareness pada penelitian ini mengacu pada penelitian Dharma dan Sukaatmaja (2015) menggunakan (1) Top Of Mind: (a) Nama merek muncul pertama kali dipikiran saat ingin membeli produk. (b) Langsung menyebutkan merek ketika membeli produk. (2) Brand Recall: (a) Secara spontan memilih merek tanpa ada pemikiran terlebih dahulu. (b) Menjadikan merek yang dipilih sebagai pilihan utama. (3) Brand Recognition. (a) Merek pernah terlintas dalam pikiran. (b) Terkadang ingat terhadap merek.

\section{Kualitas Produk}

Menurut pernyataan Kotler dan Keller (2009:143), kualitas produk adalah ciri khas suatu produk yang dapat memuaskan kebutuhan yang diinginkan oleh konsumen. Sedangkan Menurut Kotler dan Amstrong (2008:347), kualitas produk ialah semakin baik kualitas produk yang dihasilkan maka akan memberikan kesempatan pada konsumen untuk melakukan pembelian. Menurut West, Wood, dan Harger (2006), dimensi kualitas makanan terdiri dari warna, penampilan, porsi, bentuk, temperature, tekstur, aroma, tingkat kematangan, dan rasa.

Berdasarkan dimensi kualitas produk makanan dari West, Wood, dan Harger (2006), berikut adalah indikator yang digunakan dalam penelitian ini. (1)Warna: (a) Warna makanan memiliki kombinasi warna yang bagus. (b) Warna makanannya menarik hati. (2) Rasa: (a) Makanan memiliki rasa yang enak. (b) Makanan memiliki rasa yang bervariasi. (3) Tekstur (a) Makanan memiliki tekstur yang lembut. (b) Makanan memiliki tekstur yang halus. (4) Aroma (a) Makanan memilliki aroma yang menggugah selera. (b) Makanan memiliiki aroma yang harum.

\section{Hubungan antar Variabel}

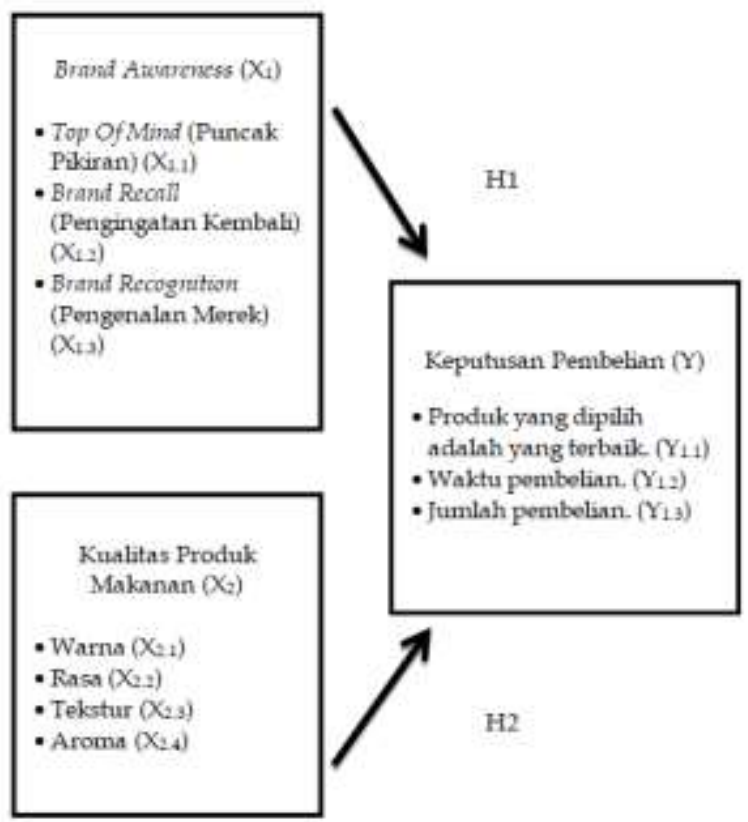

Gambar 1. KERANGKA PENELITIAN

Hubungan antar variabel digambarkan dalam Kerangka Penelitian di Gambar 1. Dalam penelitian yang dilakukan oleh Dharma dan Sukaatmaja (2015), konsumen lebih menjatuhkan pilihan terhadap merek yang mudah mereka ingat ketika konsumen ingin membeli suatu produk. Kotler dan Keller (2009:179) brand awareness/ kesadaran merek ialah kesanggupan dari konsumen untuk mendiskripsikan, mengingat, dan mengakui suatu merek dengan cukup rinci untuk melakukan pembelian. Penelitian sebelumnya juga telah membuktikan pengaruh brand awareness terhadap keputusan pembelian (Sharma \& Sonwaney, 2015; Novansa \& Ali, 2015; Khuong \& Tram, 2015). 
H1 : Terdapat pengaruh pada brand awareness terhadap keputusan pembelian.

Seperti pendapat Kotler dan Amstrong (2008:347) yang menuturkan bahwa kualitas produk ialah produk yang kualitasnya menjadi baik maka akan memberikan pengaruh pada konsumen untuk melakukan pembelian. Rijswijk dan Frewer (2008) menyatakan kriteria kualitas produk makanan yang baik meliputi rasa, aroma, bentuk, tingkat kematangan, temperature dan lain sebagainya yang akan menjadi pertimbangan konsumen dalam mengevaluasi produk yang selanjutnya mengarah pada keputusan pembelian. Penelitian sebelumnya telah membuktikan pengaruh kualitas produk terhadap keputusan pembelian (Kealesitse \& Kabama, 2012; Lee \& Hwang, 2016; Tirelli \& Martínez-Ruiz, 2014).

H2 : Terdapat pengaruh pada kualitas produk terhadap keputusan pembelian.

\section{METODE PENELITIAN}

Penelitian ini memakai rancangan penelitian konklusif. Adapun Lokasi atau tempat penelitian berada di Toko Lapis Kukus Pahlawan Jl. Kutai No. 53, Surabaya. Populasi dalam penelitian ini bersifat tidak diketahui (infinite), dengan kriteria atau karakteristik populasi pada penelitian ini yaitu konsumen yang pernah membeli di toko Lapis Kukus Pahlawan. Yang digunakan dalam penelitian ini adalah menggunakan non probabilitas sampling dengan teknik pengambilan sampel judgemental sampling. Angket diberikan ke 220 responden. Pernyataan yang digunakan dalam angket berupa pernyataan tertutup dengan menggunakan skala Likert. Pada teknik analisis data menggunakan regresi linier berganda.

\section{HASIL DAN PEMBAHASAN}

\section{Hasil Uji Validitas}

Hasil uji validitas menunjukkan seluruh item-item pernyataan yang digunakan valid karena nilai Corrected Item - Total Correlation di atas 0,361. Artinya, item-item pernyataan tersebut layak untuk pakai sebagai alat ukur ukur pada penelitian ini.

\section{Hasil Uji Reliabilitas}

Hasil pengujian reliabilitas penelitian ini dapat dilihat bahwa nilai Cronbach's Alpha untuk pengaruh brand awareness, kualitas produk dan keputusan pembelian lebih besar dari 0,70 yaitu: brand awareness 0,778 , kualitas produk 0,804 , keputusan pembelian 0,782. Sehingga, pernyataanpernyataan pada instrumen penelitian (angket) reliabel dan bisa dipakai untuk pengukuran dalam penelitian ini.

\section{Hasil Uji Asumsi Klasik}

Nilai signifikansi uji Kolmogorov Smirnov, yaitu 0.200 yang mana lebih besar dari 0.05 , artinya data yang digunakan terdistribusi secara normal. Pada uji multikolinearitas nilai tolerance kedua variabel yaitu $0.221>0.010$ artinya tidak terjadi multikoleniaritas antar variabel independent, begitu juga nilai VIF kedua variabel yaitu $4.532<10$ artinya tidak terjadi multikoleniaritas antar variabel independent. Artinya, tidak terjadi korelasi yang kuat antar varibel independen sehingga model regresi ini masih dapat ditoleransi. Pada pengujian matrik korelasi diketahui bahwa nilai matrik korelasi antar variable brand awareness dan kualitas produk adalah $0.883<0.90$, artinya tidak ada korelasi yang kuat antar variabel independen. Pada uji Hesteroskesdatisitas, tidak terjadi gangguan asumsi heteroskedastisitas artinya model regresi ini sudah baik.

\section{Hasil Uji Regresi Linear Berganda}

Pada tabel 2 bisa dilihat hasil dari analisis regresi berganda, dengan pembahasan berikut. Pada nilai konstantanya adalah 5.435 artinya reseponden jika tidak mempertimbangkan brand awareness dan kualitas produk akan tetapi lebih mempertimbangkan hal lain maka keputusan pembelian akan tetap terjadi. Nilai koefisien variabel brand awareness (X1) sebesar 1.459. terdapat tanda positif di koefisien regresi ini menandakan hubungan searah antara brand awareness (X1) terhadap keputusan pembelian (Y). yang mana jika brand awareness tinggi akan berdampak semakin tingginya keputusan 
pembelian. Nilai koefisien variabel kualitas produk (X2) sebesar 1.469. Tanda positif pada kefisien regresi melambangkan hubungan yang searah antara kualitas produk (X2) terhadap keputusan pembelian (Y). Berarti bila kualitas produk yang diberikan semakin tinggi maka akan berpengaruh pada semakin tingginya keputusan pembelian. Sedangkan nilai korelasi dan koefisien determinasi regresi berganda diketahui besarnya kontribusi variabel Brand awareness (X1) dan kualitas Produk (X2) terhadap Keputusan Pembelian (Y). Nilai Adjusted R Square sebesar 0.733=73.3\%. Sedangkan, $26.7 \%$ sisanya dipengaruhi variabel lain di luar variabel yang digunakan dalam penelitian ini. Dari tabel 2, dapat diperoleh persamaan regresi linier berganda (1).

$\mathrm{Y}=5.435+1.459 \mathrm{X} 1+1.469 \mathrm{X} 2$

Tabel 2

HASIL ANALISIS REGRESI LINIER BERGANDA

\begin{tabular}{lccccc}
\hline \multicolumn{1}{c}{ Model } & \multicolumn{2}{c}{ Unstandardized Coefficients } & Standardized Coefficients & & \\
B & Std. Error & Beta & T & Sig. \\
\hline 1 (Constant) & 5.435 & 1.085 & & 5.010 & .000 \\
Brand_awaraeness & 1.459 & .081 & 1.696 & 5.697 & .000 \\
Kualitas_Produk & 1.469 & .076 & 1.353 & 6.188 & .000 \\
a. Dependent Variable: Keputusan_pembelian & & & & \\
\hline
\end{tabular}

\section{Pengaruh Brand Awareness terhadap Keputusan Pembelian}

Hipotesis 1 dapat dibuktikan di penelitian ini. Hasil penelitian ini mendukung penelitian Sharma \& Sonwaney (2015), Novansa \& Ali (2015), dan Khuong \& Tram (2015). Berdasarkan jawaban responden, variabel brand awareness konsumen Lapis Kukus Surabaya Pahlawan berada pada tingkat brand recall.

Lapis Kukus Surabaya Pahlawan menampilkan logo khas Surabaya yaitu Tugu Pahlawan untuk membantu konsumen dalam mengidentifikasi merek tersebut dan membedakannya dengan merek lain. Hal tersebut juga mendukung positioning Lapis Kukus Surabaya Pahlawan sebagai salah satu makanan oleh-oleh khas Surabaya. Konsumen Lapis Kukus Surabaya Pahlawan seringkali membeli produk tersebut sebagai oleh-oleh ataupun hidangan saat berkumpul bersama keluarga atau tamu. Banyaknya outlet Lapis Kukus Surabaya Pahlawan dan harga produk yang terjangkau juga membuat brand awareness Lapis Kukus Surabaya Pahlawan meningkat.

Peran serta para mitra agen menjadikan semakin lama semakin meningkatkan brand awareness Lapis Kukus Surabaya pahlawan. Terbukti dengan tren yang berada di Surabaya setiap gerai mitra agen selalu dipenuhi dengan alat promosi yang sangat mencolok sehingga menjadikan Lapis Kukus Surabaya Pahlawan mudah di ingat dan dikenali masyarakat dan konsumen.

Di masa Pandemi, penjualan Lapis Kukus Surabaya Pahlawan mengalami penurunan yang signifikan. Untuk itu, Lapis Kukus Surabaya Pahlawan menggencarkan komunikasi melalui sosial media Instagram dan menyediakan layanan GoFood, delivery order, dan drive thru.. Begitu pula pada mitra Lapis Kukus Surabaya, saat ini menggencarkan komunikasi lewat sosial media, baik website instagram maupun aplikasi pengiriman makanan. Walaupun demikian, Lapis Kukus Surabaya Pahlawan tetap dicari dikala pandemi seperti ini.

Selain Lapis Kukus Surabaya Pahlawan oleh oleh khas Surabaya terdapat juga oleh-oleh yang sejenis yaitu dari kategori makanan yaitu Sambal Bu Rudy. Sambal Bu Rudy ini merupakan produk asli surabaya yang melegenda, walau sudah bertahun tahun Sambal Bu Rudy tetap eksis dan masih bertahan. Dengan dikenalinya produk Sambal Bu Rudy ini menandakan bahwa mempunyai brand awareness yang tinggi.

Selain sambal bu rudy, Surabaya Snowcake juga sempat menjadi oleh-oleh Surabaya. Dengan strategi Brand Ambassador tidak membuat mereka bisa menyaingi beberapa merek oleh-oleh yang sudah ada, 
seperti sambal bu rudy dan Lapis Kukus Surabaya. Artinya Brand awareness dari Surabaya Snowcake belum sampai tahap yang tinggi bagi konsumen, karena kini Surabaya Snowcake sudah tidak ada lagi dan tidak berjualan lagi di surabaya.

Spikoe Resep Kuno menjadi merupakan oleh-oleh Surabaya yang masih terkenal hingga saat ini. Dengan kue menggunakan kue asli Surabaya yaitu Spikoe masih menjadi merek yang dicari oleh konsumen. Konsep yang premium menjadikan oleh-oleh ini menarik. Tetapi produk ini belum bisa sampai ke seluruh segmentasi konsumen, karena dengan konsep yang premium. Di masa pandemi, penjual Spikoe Resep Kuno menjadikan media sosial sebagai alat komunikasi dengan konsumendengan melalui instagram serta beberapa aplikasi pengantar makanan.

\section{Pengaruh Kualitas Produk terhadap Keputusan Pembelian}

Penelitian ini membuktikan hipotesis 2. Hasil penelitian ini mendukung penelitian Kealesitse \& Kabama (2012), Lee \& Hwang (2016), dan Tirelli \& Martínez-Ruiz (2014). Berdasarkan jawaban responden, konsumen secara keseluruhan memperhatikan "Rasa" dari produk Lapis Kukus Surabaya.

Karakteristik responden didominasi oleh perempuan. Hal ini menunjukkan bahwa mayoritas keputusan pembelian dilakukan oleh perempuan.

Lapis Kukus Surabaya Pahlawan menjadi pilihan bagi para wisatawan karena selain produk yang menarik Lapis Kukus Surabaya Memiliki cita rasa yang enak. Sehingga, dengan kualitas yang bagus ini menjadikan Lapis Kukus Surabaya Pahlawan sebagai pilihan bagi para konsumen. Untuk menjaga kualitas produk sampai dikonsumsi konsumen, Lapis Kukus Surabaya Pahlawan juga menginformasikan tanggal produksi dan tanggal kadaluarsa di kemasan produk serta menginformasikan bagaimana cara menyimpan produk di media sosial Instagram Lapis Kukus Surabaya Pahlawan.

Kualitas produk sangat dijaga oleh perusahaan Lapis Kukus Surabaya, tidak hanya dalam isi produknya ternyata suhu ruangan dalam setiap toko Lapis Kukus Surabaya Pahlawan memiliki prosedur suhu ruangan yang harus ditaati karena dapat berpengaruh terhadap kualitas produknya. Maka dari itu setiap produk dari Lapis Kukus Surabaya Pahlawan bisa terjaga dengan baik dan selalu menjadi pilihan bagi konsumen yang berkunjung ke Surabaya.

Selain Lapis Kukus Surabaya Pahlawan, terdapat sambal bu rudy yang menjadi oleh-oleh khas Surabaya lainnya. Dengan racikan sambalnya yang sangat enak membuat banyak pecinta sambal yang sengaja datang ke Surabaya untuk membeli makanan ini sebagai oleh-oleh. Walaupun Sambal Bu Rudy sudah puluhan tahun berjualan, tetap menjadi promadona oleh-oleh bagi para wisatawan yang pergi ke Surabaya. Hal ini membuktikan bahwa dengan kualitas yang baik, akan meningkatkan pembelian terhadap suatu produk.

Surabaya Snowcake menjadi salah satu oleh-oleh dari Surabaya sempat melejit. Dengan menggandeng artis sebagai brand ambassador tidak membuat Surabaya Snowcake bertahan sampai sekarang. Saat ini Surabaya snowcake tidak ada lagi di Surabaya. Dengan menggunakan konsep Roti Pastri tidak membuat konsumen merasa terpuaskan dengan produknya. Hal ini menandakan bahwa Surabaya Snowcake tidak memiliki kualitas produk yang memuaskan konsumen sehingga tingkat pembelian menjadi rendah.

Oleh-oleh khas surabaya legendaris lainnya adalah Spikoe Resep Kuno. Dengan menggunakan roti spikoe asli surabaya, membuat produk ini tetap dicari oleh wisatawan yang singgah di Surabaya. Dengan konsep Premium dan kualitas produk yang baik menjadikan Spikoe Resep Kuno masih bertahan hingga saat ini. Meskipun roti Spikoe adalah roti jaman dulu dengan produk yang sangat baik membuat Spikoe Resep Kuno tetap menjadi pilihan bagi konsumen. Artinya dengan kualitas produk yang baik dan terjaga dapat berpengaruh juga pada pembelian suatu produk. 


\section{KESIMPULAN}

Berdasar penelitian yang dilakukan dapat diambil kesimpulan bahwa terdapat pengaruh signifikan antara brand awareness terhadap keputusan pembelian konsumen Lapis Kukus Pahlawan. Selain itu, terdapat pengaruh yang positif pada kualitas produk terhadap keputusan pembelian konsumen Lapis Kukus Pahlawan.

Pelaku usaha diharapkan selalu berupaya menjaga dan membangun Brand awareness dan meningkatkan kualitas produk yang diberikan, agar mampu menarik konsumen untuk melakukan keputusan pembelian. Hal tersebut juga penting bagi Lapis Kukus Pahlawan agar brand awareness konsumen meningkat terhadap Lapis Kukus Surabaya dan juga kualitas harus tetap dijaga dan dikembangkan agar semakin banyak konsumen yang memutuskan untuk membeli Lapis Kukus Pahlawan.

Keterbatasan dalam penelitian ini adalah menentukan variabel penelitian hanya brand awareness, kualitas produk, dan keputusan pembelian sehingga hasil yang didapat kurang bisa menyeluruh. Penelitian selanjutnya dapat melibatkan variabel lain seperti citra merek, harga, dan komunikasi pemasaran yang dilakukan.

\section{DAFTAR PUSTAKA}

Aaker, David A. 1997. Ekuitas Merek. Edisi Indonesia. Jakarta: Mitra Utama.

Antonius, I., Sugiono, D., \& Pemasaran. 2013. Analisa Pengaruh Strategi Diferensiasi, Citra Merek, Kualitas Produk Dan Harga Terhadap Keputusan Pembelian Pelanggan Di Cincau Station Surabaya. Jurnal Menejemen Pemasaran, Universitas Kristen Petra 1(2), 1-11.

Dharma dan Sukaatmaja (2015), Pengaruh Citra Merek, Kesadaran Merek dan Kualitas Produk Terhadap Keputusan Membeli Produk Apple. E-Jurnal Manajemen Universitas Udayana, 4(10), 3228-3255.

Kealesitse, B., \& Kabama, I. O. (2012). Exploring the influence of quality and safety on consumers' food purchase decisions in Botswana. International Journal of Business Administration, 3(2), 90 .

Khuong, M. N., \& Tram, V. N. B. (2015). The effects of emotional marketing on consumer product perception, brand awareness and purchase decision-A study in ho chi Minh City, Vietnam. Journal of Economics, Business and Management, 3(5), 524-530.

Kotler dan Amstrong. 2008. Prinsip-prinsip Pemasaran. Edisi 12. Jakarta: Erlangga.

Kotler, P., Keller, K.L. 2009. Manajemen Pemasaran. Edisi 13, Jakarta: PT. Indeks,.

Lee, H. J., \& Hwang, J. (2016). The driving role of consumers' perceived credence attributes in organic food purchase decisions: A comparison of two groups of consumers. Food quality and preference, 54, 141-151.

Novansa, H., \& Ali, H. (2017). Purchase Decision Model: Analysis of brand image, brand awareness and price (Case study SMECO Indonesia SME products). Saudi Journal of Humanities and Social Sciences, 2(8), 621-632.

Okkysantria, Dyca. 203. Pengaruh Kebudayaan, Sosial, Pribadi dan Psikologis Konsumen Usia Muda Terhadap Keputusan Pembelian Makan Cepat Saji McDonald's (Studi Kasus pada Konsumen McDonald's Watugong Malang). Jurnal Skripsi Bidang Manajemen Pemasaran Jurusan Manajemen Fakultas Ekonomi dan Bisnis Unversitas Brawijaya. 
Candra Purba Wisesa. Studi Keputusan Pembelian Makanan Oleh-Oleh Khas Surabaya: Peran Brand Awareness dan Kualitas Produk

Sharma, A., \& Sonwaney, V. (2015). Exploring the role of family communication and brand awareness in understanding the influence of child on purchase decisions: Scale development and validation. International Journal of Business Excellence, 8(6), 748-766.

Tirelli, C., \& Martínez-Ruiz, M. P. (2014). Influences of product attributes on sojourners' food purchase decisions. British Food Journal.vol116 issue 2.

Tourdejava.com. 2015. Surabaya, Kota Kenangan Para Pahlawan. (https://www.tourdejava.net/2015/12/wisata-jejajah-kota-surabaya.html diakses pada 2 Desember 2017).

Yaphyaputra, Vicky dan Maichal (2018). Pengaruh Brand Awareness Dan Brand Image Terhadap Keputusan Pembelian Produk Sealantwax Di Surabaya. PERFORMA: Jurnal Manajemen dan Start-Up Bisnis Volume 3, Nomor 2.

West B.B, Wood L, Harger VP. 2006.Food Service in Intituitions. New York : John Willey and Sons, Inc. 